Article

\title{
Silica-Milled Paulownia Biochar as Partial Replacement of Carbon Black Filler in Natural Rubber
}

\author{
Steven C. Peterson \\ Plant Polymer Research, National Center for Agricultural Utilization Research, \\ Peoria, IL 61604, USA; Steve.Peterson@usda.gov; Tel.: +1-309-681-6325
}

Received: 25 September 2019; Accepted: 11 December 2019; Published: 13 December 2019

\begin{abstract}
Carbon black (CB) has been the dominant filler in the tire industry for decades. The demand for this petroleum byproduct is ever increasing, although petroleum markets can be volatile due to geopolitical issues. Finding sustainable, renewable substitutes for $\mathrm{CB}$ reduces the dependence on petroleum. Biochar is a renewable source of carbon that was studied as a potential CB replacement filler in styrene-butadiene rubber (SBR) composites, but little has been done in terms of natural rubber (NR). In this work, biochar made from fast-growing Paulownia elongata was co-milled with small amounts of silica in order to reduce the larger particle size typical with biochar respective to $C B$. The resulting silica-milled Paulownia biochar (PB) was then used to replace CB in natural rubber (NR) composites. By using this method to make natural rubber composites with $30 \%$ total filler, half of the $\mathrm{CB}$ was fully replaced with silica-milled biochar with very little loss $(<6 \%)$ of tensile strength, and equal or better elongation and toughness compared to the $100 \%$ CB-filled control composite.
\end{abstract}

Keywords: Paulownia; biochar; carbon black; natural rubber; silica

\section{Introduction}

Natural rubber (NR) is an organic, elastic substance obtained from the sap of trees, and it is the precursor to modern synthetic rubber products. Although synthetic rubber composites have a larger market share than NR in most industrial applications today, NR is still a crucial and necessary material used in tire, hose, medical tubing, and barrier applications (NR is an excellent pathogen barrier). NR typically disperses heat better than synthetic rubber when strained and has better tear resistance at higher temperatures, making it advantageous for heavy-vehicle tires such as trucks and buses [1].

For roughly a century, the dominant filler used to strengthen NR has been carbon black (CB), a material manufactured from petroleum, because of its superior purity as a form of carbon along with its excellent reinforcement properties [2]. However, fossil fuel-based materials are not sustainable; thus, renewable substitutes for $C B$ need to be explored to prepare for a time when fossil fuels become scarce. Biochar is a material that has great potential to replace $C B$ since it is a solid source of carbon produced from the thermochemical treatment of biomass in the absence of oxygen [3]. Past studies showed that biochars made from wood-based feedstocks have a higher carbon content and lower ash content than other types of low-value renewable feedstocks such as grasses, corncobs, or manures $[4,5]$; hence, wood-based feedstocks would be a logical candidate if biochar mimicking carbon black is the desired outcome.

Paulownia elongata is a fast-growing hardwood tree that generated interest as a bioenergy crop due to its growth rate and ability to be coppiced (wood cut from the main stump is harvested and the regrowth from that stump can be re-harvested periodically) [6]. Paulownia plantations in Georgia with 1680 trees per hectare are expected to yield 100 tons of biomass after three years [7], and another study 
reported that 2000 trees per hectare produced 300 tons of hardwood annually beginning six years after planting [8]. Paulownia is a robust tree that can grow well in hardiness zones 6-11 [9], which means it could grow over virtually the entire southeastern United States from the Carolinas to Texas. It is currently used as a filler for wood-plastic composites [10], and biochar made from it was studied as a horticultural amendment to soil [11].

Biochars made from hardwood were previously tested as filler for styrene-butadiene rubber [12,13], but they were not successful mainly because of two significant differences regarding purity and particle size. Because biochar is usually made from a "top-down" method of pyrolyzing the biomass and then grinding the solid carbonaceous product, it is difficult to match both the nano-sized particulates of $\mathrm{CB}$ and the monodispersity of the CB structures using cost-effective milling methods. Previously milled biochars would have a certain population of particles with diameters of $10-100 \mu \mathrm{m}$. This is problematic in rubber composite samples because even a small amount of these larger biochar particles will cause localized stresses to develop and significantly weaken the composite in terms of tensile strength via fracture, tearing, or other types of defects. To improve this, recent work (using SBR as the rubber matrix) was done utilizing silica co-milling of biochar in which a very small amount of silica was added to the ball milling process in order to help reduce the particle size of biochar [14]. Because silica is very hard (hardness of $\sim 6-7 \mathrm{GPa}$ ) and an excellent rubber reinforcing material on its own, it does an excellent job of shearing apart larger biochar agglomerates and does not need to be removed from the biochar post-milling. Thus, silica co-milling with biochar is much more efficient and significantly reduces the number of biochar agglomerates $>10 \mu \mathrm{m}$. This increases the maximum packing fraction [15] of the biochar filler and should allow a higher amount of $C B$ to be replaced with biochar.

In this work, biochar created from Paulownia elongata hardwood feedstock that was co-milled with silica in order to reduce the particle size was substituted for CB in composites using NR as the rubber matrix. The tensile strength, elongation, and toughness of these composites were compared with a 100\% CB-filled control composite to determine to what extent CB could be replaced with Paulownia biochar $(\mathrm{PB})$ while still retaining the same desirable tensile properties as the control.

\section{Materials and Methods}

\subsection{Materials Used}

Biochar made from Paulownia elongata using a proprietary method was supplied by Biochar Options (Whitewater, WI, USA). The CB control used was Vulcan M brand N-339 produced by the Cabot Corporation (Alpharetta, GA, USA). Technically specified grade natural rubber was supplied by Michelin (Greenville, SC, USA) and used as provided. The silica used in this work was Agilon performance silica 400GD supplied by PPG Industries (Pittsburgh, PA, USA) and used without further modification.

\subsection{Chemical and Physical Material Properties}

Elemental analysis of carbon $(\mathrm{C})$ and hydrogen $(\mathrm{H})$ was carried out using a Perkin Elmer 2400 $\mathrm{CHNS/O}$ series II analyzer (Norwalk, CT, USA) using cysteine as a standard. Each measurement used approximately $2 \mathrm{mg}$ of $\mathrm{PB}$ and was done in triplicate. Ash content was determined using a TA Instruments Q2950 thermogravimetric analyzer (New Castle, DE, USA) by heating to $1000{ }^{\circ} \mathrm{C}$ at a heating rate of $10^{\circ} \mathrm{C} \cdot \mathrm{min}^{-1}$ in an air atmosphere. Ash content was determined to be the weight percentage remaining, and oxygen $(\mathrm{O})$ was determined by difference from the original dried sample and the sum of $\mathrm{C}, \mathrm{H}$, and ash. PB absolute density was measured as detailed in a previous manuscript [13].

Fourier-transform infrared (FTIR) spectra of PB and CB were collected using a Thermo Nicolet iS10 (Waltham, MA, USA) with a SensIR Technologies Durascope dATR attachment. Peaks were determined manually after obtaining the average absorbance values from 128 scans per sample.

Resistivity measurements were conducted using an Electro-Tech Systems Inc. (Glenside, PA, USA) Autoranging Resistance Indicator Model 880. Measurements in the conductive range $\left(<5 \times 10^{5}\right)$ were 
made at $10 \mathrm{~V}$ while all other measurements were made at $100 \mathrm{~V}$. Accuracy was $\pm 10 \%$ with changeover points of one half-decade on a log scale.

X-ray diffractograms of $\mathrm{PB}$ and $\mathrm{CB}$ were obtained by using a Bruker D2 Phaser (Billerica, MA, USA) using $\theta / \theta$ geometry and $\mathrm{Cu}-\mathrm{K} \alpha$ radiation generated at a current of $10 \mathrm{~mA}$ and $30 \mathrm{kV}$. Scans were run over a $2 \theta$ range of $5^{\circ}-90^{\circ}$ with a step size of $0.02^{\circ}$ and a time per step of $0.2 \mathrm{~s}$. Initial divergence slit size was $0.6 \mathrm{~mm}$, and a 1-mm air scatter screen was used above the sample. The sample stage was rotated at $10 \mathrm{rpm}$ during the scan. A Lynxeye $\mathrm{T}^{\mathrm{TM}}$ detector was used in conjunction with a $2.5^{\circ}$ Soller slit and an $\mathrm{Ni}-\mathrm{K} \alpha$ filter.

SEM images for CB and PB were collected on separate systems at different times; the PB images were more recent and used an updated SEM. The CB image was obtained by mounting CB onto aluminum stubs with conductive carbon tape and then sputter-coating them with $\mathrm{Au}-\mathrm{Pd}$. The $\mathrm{CB}$ was then examined with a JEOL 6400 V (JEOL USA, Inc., Peabody, MA, USA) scanning electron microscope. $\mathrm{PB}$ images were obtained in a similar fashion; $\mathrm{PB}$ was sputter-coated with $\mathrm{Au}$ and then examined using a JEOL JSM-6020LA analytical scanning electron microscope.

\subsection{Formation of Rubber Composites and Tensile Testing}

PB was milled with silica to reduce larger-sized particles as detailed in a previous manuscript [16]. Rubber composites were formulated using a C.W. Brabender Intelli-Torque Plasti-Corder torque rheometer (South Hackensack, NJ, USA), using a 75-mL three-piece mixer equipped with Banbury blades. The mixer was loaded to the recommended $70 \%$ volume of approximately $53 \mathrm{~g}$, depending on composite density, which was calculated for each sample. Initial mixing was at $60 \mathrm{rpm}$ and $120{ }^{\circ} \mathrm{C}$. Then, NR was added, the loading ram chute was mounted, and then 2,2,4-trimethyl-1,2-dihydroquinone, $N$-1,3-dimethylbutyl- $N$-phenyl-p-phenylene diamine, $\mathrm{CB}$ and/or PB filler, zinc oxide, and stearic acid were added. Silica-milled biochar dispersed well and did not agglomerate. The piston was then stabilized by a 5.0-kg weight placed on top and allowed to continue mixing at $120{ }^{\circ} \mathrm{C}$ for a total of $10 \mathrm{~min}$. The sample was then removed and sheeted out using an MTI HR01 hot rolling machine (Richmond, CA, USA) with a nip setting of $2 \mathrm{~mm}$ and a roller temperature of $25{ }^{\circ} \mathrm{C}$. The mixer was then set to $100{ }^{\circ} \mathrm{C}$, and the sheeted sample, sulfur, and $\mathrm{N}$-cyclohexyl-2-benzothiazolesulfenamide were added and mixed for an additional $3 \mathrm{~min}$. The gram amounts of each of these ingredients for the various rubber composite samples tested in this work are shown in Table 1. The finished composite was then sheeted an additional time in the hot rolling machine with the same settings as the first pass. Approximately $20 \mathrm{~g}$ of the sheeted composite was loaded into a $102 \times 102 \times 2 \mathrm{~mm}$ window-type mold and placed in a Carver press preheated to $160{ }^{\circ} \mathrm{C}$, where it was then compressed at $89 \mathrm{kN}$ for $20 \mathrm{~min}$, after which the press was cooled for $25 \mathrm{~min}$ under pressure, and then the sample was removed.

Composite sample bars were cut using an ISO 37-2 cutting die. Samples were conditioned at $23 \pm 1{ }^{\circ} \mathrm{C}$ and $50 \% \pm 10 \%$ relative humidity for at least $24 \mathrm{~h}$ after molding. Testing was performed on an Instron 55R1123C5420 (Instron, Inc., Norwood, MA, USA) using Bluehill Software version 3.61. Tensile tests were run using a crosshead speed of $500 \mathrm{~mm} / \mathrm{min}$ and a 1-kN load cell, as specified by ASTM D412. Tensile tests directly measured the stress and strain of each rubber composite sample, and toughness was calculated as the area under the stress/strain curve by the software.

Small-strain oscillation sweeps were made on a TA Instruments (New Castle, DE, USA) ARES G2 controlled-strain rheometer using 8-mm cross-hatched plates at $25^{\circ} \mathrm{C}$. Each sample was placed under a $0.1 \%$ strain (within the linear region) with a frequency of $1 \mathrm{~Hz}$ and cycled 1000 times, while the storage modulus $\left(G^{\prime}\right)$ was recorded for each cycle. 
Table 1. 30\% Total Filler Control and Composite Formulations (g).

\begin{tabular}{cccccccccc}
\hline Filler Composition & NR & TMQ & 6PPD & CB & PB & $\begin{array}{c}\text { Stearic } \\
\text { Acid }\end{array}$ & ZnO & Sulfur & CBTS \\
\hline unfilled NR & 46.66 & 0.23 & 0.23 & 0 & 0 & 0.93 & 2.33 & 1.17 & 0.47 \\
100\% CB & 39.19 & 0.20 & 0.20 & 16.79 & 0 & 0.78 & 1.96 & 0.98 & 0.39 \\
0\% silica/100\% PB & 38.43 & 0.19 & 0.19 & 0 & 16.47 & 0.77 & 1.92 & 0.96 & 0.38 \\
0.5\% silica/100\% PB & 38.43 & 0.19 & 0.19 & 0 & 16.47 & 0.77 & 1.92 & 0.96 & 0.38 \\
1\% silica/100\% PB & 38.43 & 0.19 & 0.19 & 0 & 16.47 & 0.77 & 1.92 & 0.96 & 0.38 \\
2\% silica/100\% PB & 38.43 & 0.19 & 0.19 & 0 & 16.47 & 0.77 & 1.92 & 0.96 & 0.38 \\
1\% silica-75/25\% PB/CB & 38.62 & 0.19 & 0.19 & 4.14 & 12.41 & 0.77 & 1.93 & 0.97 & 0.39 \\
$1 \%$ silica-50/50\% PB/CB & 38.81 & 0.19 & 0.19 & 8.31 & 8.31 & 0.78 & 1.94 & 0.97 & 0.39 \\
\hline
\end{tabular}

NR: natural rubber; TMQ: 2,2,4-trimethyl-1,2-dihydroquinone; 6PPD: $N$-1,3-dimethylbutyl- $N$-phenyl-p-phenylene diamine; CB: carbon black; PB: Paulownia biochar; ZnO: zinc oxide; CBTS: $N$-cyclohexyl-2-benzothiazolesulfenamide.

\section{Results}

\subsection{Biochar Characterization}

$\mathrm{CB}$ is a very pure form of carbon $(>99 \%)$, with less than $1 \%$ hydrogen, oxygen, and ash, and a density of 1.7-1.9 $\mathrm{g} / \mathrm{cm}^{3}$ (data supplied by the manufacturer). The PB used in this study had a density of $1.75 \mathrm{~g} / \mathrm{cm}^{3}$ and an ash content of $2.90 \%$. Elemental composition of the PB was $92.68 \%$ $\pm 0.57 \%$ carbon, $0.94 \% \pm 0.05 \%$ hydrogen, and $3.48 \%$ oxygen (by difference). Similar to a previous study [16], the FTIR spectrum of PB was devoid of any functional group peaks, as would be expected from a nearly pure carbon material. The FTIR spectra of the PB and the CB used in this study can be seen in Figure 1, along with the X-ray diffraction spectra of both CB and PB. Both materials showed the characteristic carbon black graphitic $d$-spacing peaks at approximately $24^{\circ}$ and $43^{\circ} 2 \theta$ [17]. Neither sample showed any strong and/or sharp peaks that would indicate a significant amount of crystalline impurities, which was corroborated by both samples having $>92 \%$ carbon content.

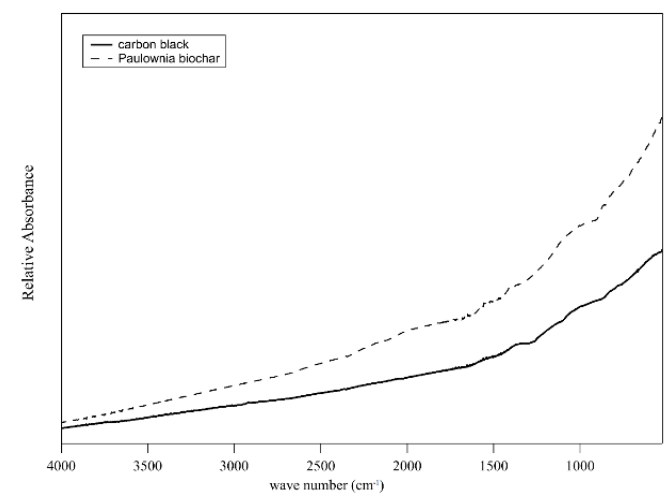

(a)

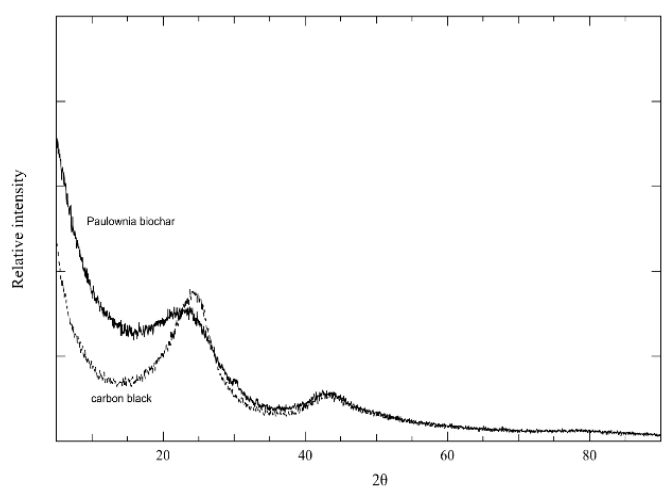

(b)

Figure 1. (a) Fourier-transform infrared (FTIR) spectra of carbon black (CB) and Paulownia biochar (PB). No sharp functional groups peaks are evident; (b) X-ray diffraction spectra of carbon black and Paulownia biochar. Both traces show the characteristic CB graphitic $d$-spacing peaks at $24^{\circ}$ and $43^{\circ} 2 \theta$.

Figure 2 shows SEM images of PB, both pre (a) and post (b) silica milling. These images illustrate the effective particle size reduction effect of milling biochar with silica. Images (c) and (d) show CB and post-silica-milled $\mathrm{PB}$, respectively, at higher magnification. The typical aggregate and agglomerate structures of CB are seen in image (c); CB aggregates are typically 50-500 $\mathrm{nm}$ in size and can be seen in the image as the smaller spheres that make up the three primary larger agglomerates in the picture, each of which was several microns in diameter. Even though CB agglomerates and PB particles are not terribly different in size (both on the order of microns), CB agglomerates break down rather easily into the aforementioned $\mathrm{CB}$ aggregates with shearing forces that are commonly attained during rubber 
mixing/compounding. PB particles are more polydisperse and do not break down as easily; thus, if larger PB particles are present, they can cause local stresses in the rubber composite matrix that translate into lower tensile strength.

(a)

(c)

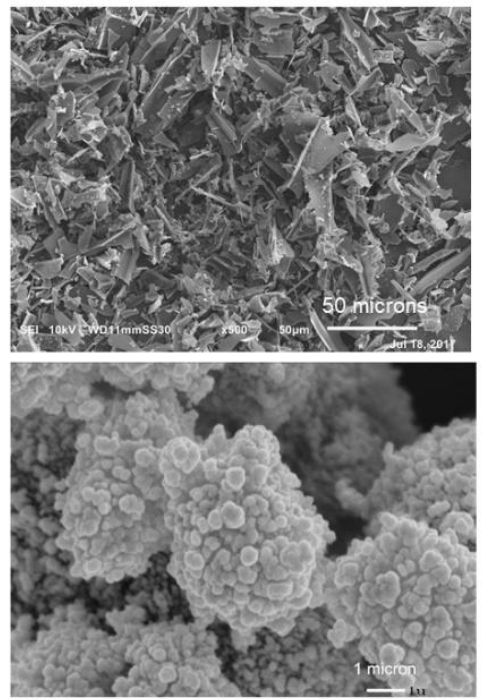

(b)

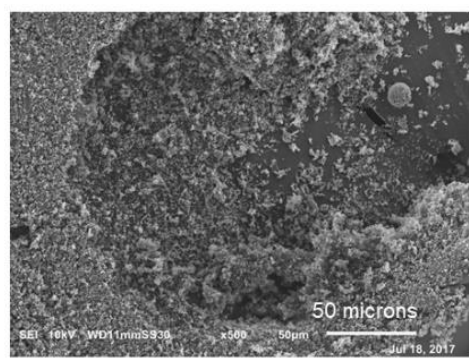

(d)

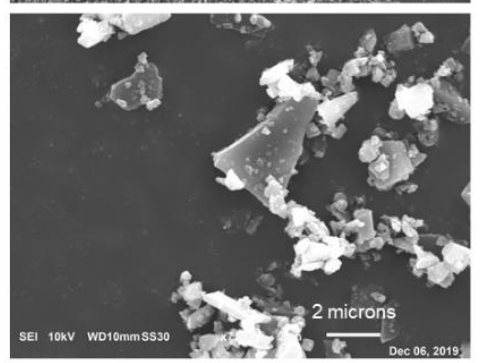

Figure 2. (a) SEM image of PB before silica milling and (b) after silica milling. For (a,b), the magnification is only $500 \times$, and the white bar in the lower right corner represents 50 microns. (c) SEM image of CB structure at 10,000 $\times$ magnification; the white bar in the lower right corner represents one micron; (d) SEM image of PB post silica milling at 7500× magnification to compare with CB; note the slight scale change where the white bar represents two microns.

\subsection{Composite Properties}

All composite samples were measured for their electrical resistivity, but only the CB control sample registered a resistance of $10^{5} \Omega$, which is classified as conductive $\left(10^{3}-10^{5} \Omega\right)$. All of the other samples containing PB at any concentration registered the same resistance of $10^{12} \Omega$, classified as insulative. Unfilled NR had a resistance of $10^{11} \Omega$, classified as static dissipative [18].

In this work, PB was milled with $0.5,1$, or 2 wt.\% silica. Previous work in our lab showed us that milling with greater than $10 \mathrm{wt} . \%$ silica was detrimental to strength and toughness properties of the final composites. For previous SBR composites, $1 \%$ silica was optimal for biochar particle size reduction and favorable tensile properties; thus, that dictated our range in this study. Tensile properties for the NR composites are shown in Table 2. NR is a very soft rubber that needs to be reinforced for most real-world applications; this is illustrated in the tensile results for unfilled NR vs. the $100 \%$ CB-filled control. The CB-filled control had over twice the tensile strength and toughness, although this added strength did reduce the elongation at break.

Table 2. Tensile properties of NR composites with $30 \mathrm{wt} . \%$ total filler. N/A-not applicable.

\begin{tabular}{cccccccc}
\hline Filler & Silica (\%) & $\boldsymbol{n}$ & $\begin{array}{c}\text { CB } \\
\text { Replaced } \\
(\%)\end{array}$ & $\begin{array}{c}\text { Tensile } \\
\text { Strength } \\
\mathbf{( M P a )}\end{array}$ & $\begin{array}{c}\text { Elongation } \\
\mathbf{( \% )}\end{array}$ & $\begin{array}{c}\text { Toughness } \\
\mathbf{( M P a )}\end{array}$ & $\begin{array}{c}\text { Young's } \\
\mathbf{M o d u l u s} \\
\mathbf{( M P a})\end{array}$ \\
\hline Unfilled NR & 0 & 6 & N/A & $11.9 \pm 1.2$ & $626 \pm 9$ & $19.4 \pm 1.6$ & $1.2 \pm 0.1$ \\
$100 \%$ CB & 0 & 6 & 0 & $25.7 \pm 0.6$ & $476 \pm 8$ & $51.7 \pm 2.3$ & $3.9 \pm 0.4$ \\
$100 \%$ PB & 0 & 9 & 100 & $15.3 \pm 1.6$ & $522 \pm 21$ & $32.2 \pm 4.7$ & $1.9 \pm 0.3$ \\
$100 \%$ PB & 0.5 & 5 & 100 & $18.9 \pm 0.7$ & $516 \pm 10$ & $39.3 \pm 2.2$ & $2.2 \pm 0.3$ \\
$100 \%$ PB & 1 & 6 & 100 & $19.3 \pm 0.9$ & $519 \pm 8$ & $40.1 \pm 2.3$ & $2.2 \pm 0.3$ \\
$100 \%$ PB & 2 & 9 & 100 & $17.3 \pm 1.2$ & $469 \pm 20$ & $32.4 \pm 3.9$ & $2.3 \pm 0.4$ \\
$75 / 25 \%$ PB/CB & 1 & 6 & 75 & $21.0 \pm 0.9$ & $524 \pm 11$ & $43.9 \pm 2.6$ & $2.2 \pm 0.2$ \\
$50 / 50 \%$ PB/CB & 1 & 6 & 50 & $24.3 \pm 0.4$ & $527 \pm 12$ & $52.3 \pm 1.4$ & $2.8 \pm 0.3$ \\
\hline
\end{tabular}


The next four rows show NR with $100 \%$ PB filler replacing the $\mathrm{CB}$, with varying silica concentration. In terms of tensile strength and toughness, $0.5 \%$ and $1 \%$ silica provided the best results, at roughly 19 and $40 \mathrm{MPa}$, respectively; however, these data are significantly lower than the CB control. Elongation was improved in each of these samples except for the one with $2 \%$ silica. The CB-filled control was a stiffer composite compared to the biochar-substituted composites; this was reflected in both the increased elongation behavior and decreased Young's modulus behavior. To see if the tensile properties of PB-filled NR composites could be improved, PB milled with $1 \%$ silica was blended with CB at ratios of $75 / 25$ and 50/50 PB/CB. The results for these composites are shown as the final two rows of Table 2 . Tensile strength decreased with increasing PB filler, but the composite that replaced $50 \%$ of the CB with $1 \%$ silica-milled PB nearly matched the CB control in tensile strength (5.5\% lower) and surpassed the control in terms of elongation and toughness, but had a lower Young's modulus. The stress-strain curves of the 1\% silica-milled composites are also shown in Figure 3. The reduced stiffness of the biochar-substituted samples suggested that, although these composites had similar strength and enhanced toughness, they may be better suited toward applications that favor increased flexibility, such as tubing.

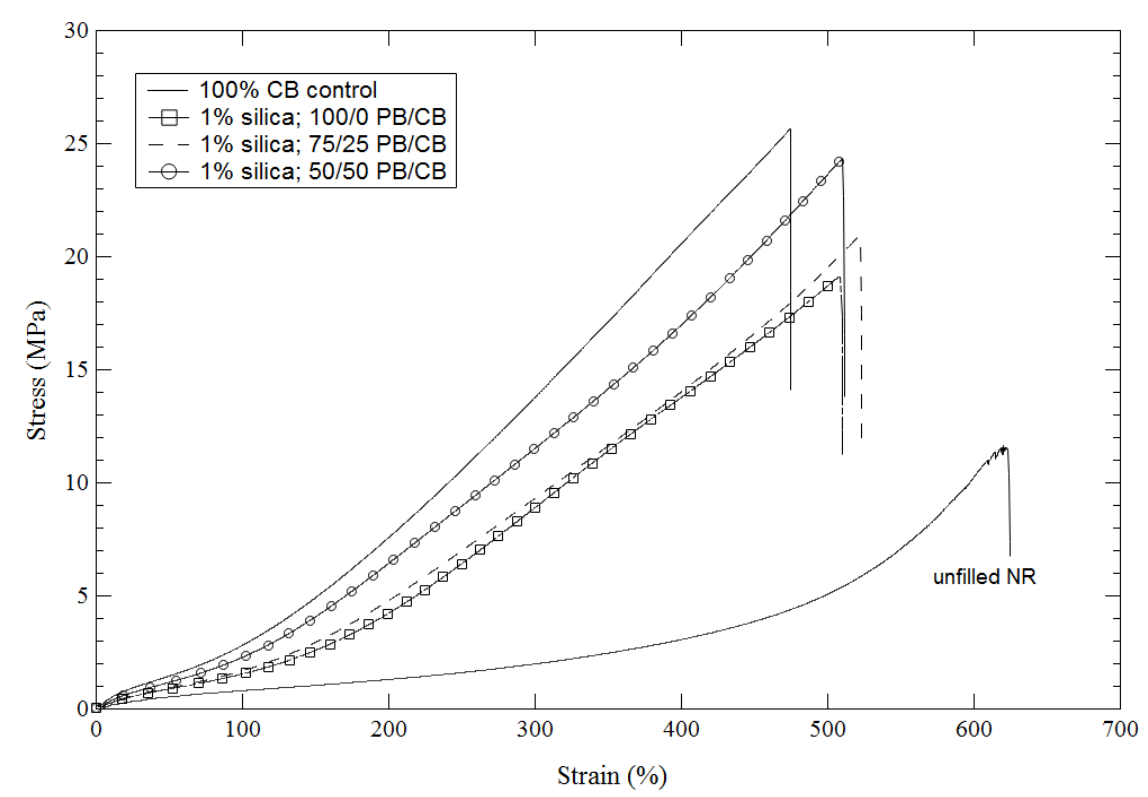

Figure 3. Stress-strain curves of the PB composites milled with $1 \%$ silica. It can be seen that, by increasing the amount of $\mathrm{CB}$ in the $\mathrm{PB} / \mathrm{CB}$ ratio, the PB-substituted composites approach the performance of the $\mathrm{CB}$ control, with the 50/50 $\mathrm{PB} / \mathrm{CB}$ composite (open circles) having slightly lower tensile strength and slightly higher elongation than the CB control (solid line).

Small-strain oscillation sweeps were carried out on the composite samples at $0.1 \%$ strain (well within the linear region) at a frequency of $1 \mathrm{~Hz}$ for 1000 cycles. All the composites showed constant storage modulus $\left(G^{\prime}\right)$ values, and these values are shown in Table 3. The CB control showed the highest $G^{\prime}$ value, indicating the stiffest sample. The results did not show a clear trend in terms of silica concentration; rather, $\mathrm{G}^{\prime}$ of the composite seemed much more dependent on $\mathrm{CB}$ concentration. 
Table 3. Small-strain cyclic behavior of NR composites with $30 \mathrm{wt}$.\% total filler.

\begin{tabular}{cc}
\hline Sample & Average $\mathbf{G}^{\prime} \mathbf{( M P a )}$ \\
\hline Unfilled NR & $0.256 \pm 0.001$ \\
$100 \% \mathrm{CB}$ & $1.18 \pm 0.02$ \\
$100 \% \mathrm{~PB}-0 \% \mathrm{Si}$ & $0.397 \pm 0.001$ \\
$100 \% \mathrm{~PB}-0.5 \% \mathrm{Si}$ & $0.362 \pm 0.002$ \\
$100 \% \mathrm{~PB}-1 \% \mathrm{Si}$ & $0.357 \pm 0.001$ \\
$100 \% \mathrm{~PB}-2 \% \mathrm{Si}$ & $0.410 \pm 0.001$ \\
$75 / 25 \mathrm{~PB} / \mathrm{CB}$ & $0.445 \pm 0.003$ \\
$50 / 50 \mathrm{~PB} / \mathrm{CB}$ & $0.609 \pm 0.004$ \\
\hline
\end{tabular}

As biochar research continues, the challenge will be to cost-effectively improve sustainable biochar in terms of (increasing) carbon content, (reducing) ash content, and (reducing) particle size in order to make it a more worthy replacement for $\mathrm{CB}$ that does not sacrifice material properties.

\section{Conclusions}

P. elongata is a rapidly growing, sustainable source of hardwood that can be grown over a wide geographical footprint of the southern United States. This tree has a wide variety of potential uses including the production of honey [6], biocomposites [19-21], pencils [22], medicinal compounds [23], timber [24], and biomass [25]. Biochar made from P. elongata showed promise for athletic turf application [26] and other broader-based horticultural applications [11].

In this work, PB that was co-milled with silica to reduce its particle size was used as a direct substitute for carbon black in NR composites. Although there was some improvement in the elongational properties, the tensile strength and toughness properties of $100 \%$ PB filled NR composites were significantly lower than the $\mathrm{CB}$ control. By blending $\mathrm{PB}$ and $\mathrm{CB}$ in different ratios, it was found that a 50/50 blend of $\mathrm{PB} / \mathrm{CB}$ yielded a composite that was only $6 \%$ lower in tensile strength while surpassing the $100 \% \mathrm{CB}$ control in both elongation and toughness properties.

Funding: This research received no external funding.

Acknowledgments: The author would like to thank Steve Nichols of Biochar Options for providing biochar samples, Liz Krietemeyer for obtaining FTIR spectra, and Andrew James Thomas for composite preparation, tensile properties, and density and ash measurement. Mention of trade names or commercial products in this article is solely for the purpose of providing scientific information and does not imply recommendation or endorsement by the U.S. Department of Agriculture. USDA is an equal opportunity provider and employer.

Conflicts of Interest: The authors declare no conflicts of interest.

\section{References}

1. An Unknown Object, the Tire: Materials. Available online: Thetiredigest.michelin.com/an-unknown-objectthe-tire-materials (accessed on 6 September 2019).

2. Spahr, M.; Rothon, R. Carbon black as a polymer filler. In Polymers and Polymeric Composites: A Reference Series, 1st ed.; Palsule, S., Ed.; Springer: Berlin/Heidelberg, Germany, 2016; Volume 4, pp. 1-31. ISSN 2510-3458.

3. Lehmann, J.; Joseph, S. Biochar for Environmental Management: Science and Technology, 2nd ed.; Routledge: New York, NY, USA, 2015; p. 976. ISBN 0415704154.

4. Mukome, F.N.D.; Zhang, X.; Silva, L.C.R.; Six, J.; Parikh, S.J. Use of chemical and physical characteristics to investigate trends in biochar feedstocks. J. Agric. Food Chem. 2013, 61, 2196-2204. [CrossRef] [PubMed]

5. Demirbas, A. Effects of temperature and particle size on bio-char yield from pyrolysis of agricultural residues. J. Anal. Appl. Pyrolysis 2004, 72, 243-248. [CrossRef]

6. Yadav, N.K.; Vaidya, B.N.; Henderson, K.; Lee, J.F.; Stewart, W.W.; Dhekney, S.A.; Joshee, N. A review of Paulownia biotechnology: A short rotation, fast growing multipurpose bioenergy tree. Am. J. Plant Sci. 2014, 4, 2070-2082. [CrossRef]

7. Basu, C.; Joshee, N.; Gezalian, T.; Vaidya, B.N.; Satidkit, A.; Hemmati, H.; Perry, Z.D. Cross-species PCR and field studies on Paulownia elongata: A potential bioenergy crop. Bioethanol 2016, 2, 12-23. [CrossRef] 
8. Jiménez, L.; Rodríguez, A.; Ferrer, J.L.; Pérez, A.; Angulo, V. Paulownia, a fast-growing plant, as a raw material for paper manufacturing. Afinidad 2005, 62, 100-105.

9. Paulownia Growing Zones. Available online: worldpaulownia.com/growing-zones (accessed on 6 September 2019).

10. Ayrilmis, N.; Kaymakci, A. Fast growing biomass as reinforcing filler in thermoplastic composites: Paulownia elongata wood. Ind. Crop. Prod. 2013, 43, 457-464. [CrossRef]

11. Vaughn, S.F.; Kenar, J.A.; Tisserat, B.; Jackson, M.A.; Joshee, N.; Vaidya, B.N.; Peterson, S.C. Chemical and physical properties of Paulownia elongata biochar modified with oxidants for horticultural applications. Ind. Crop. Prod. 2017, 97, 260-267. [CrossRef]

12. Peterson, S.C. Utilization of low-ash biochar to partially replace carbon black in styrene-butadiene rubber composites. J. Elastomers Plast. 2013, 45, 487-497. [CrossRef]

13. Peterson, S.C.; Chandrasekaran, S.R.; Sharma, B.K. Birchwood biochar as partial carbon black replacement in styrene-butadiene rubber composites. J. Elastomers Plast. 2015, 48, 305-316. [CrossRef]

14. Peterson, S.C.; Kim, S. Reducing biochar particle size with nanosilica and its effect on rubber composite reinforcement. J. Polym. Environ. 2019. [CrossRef]

15. Gent, A.N.; Pulford, C.T.R. Micromechanics of fracture in elastomers. J. Mater. Sci. 1984, 19, 3612-3619. [CrossRef]

16. Peterson, S.C.; Joshee, N. Co-milled silica and coppiced wood biochars improve elongation and toughness in styrene-butadiene elastomeric composites while replacing carbon black. J. Elastomers Plast. 2018, 50, 667-676. [CrossRef]

17. Darmstadt, H.; Roy, C.; Kaliaguine, S.; Xu, G.; Auger, M.; Tuel, A.; Ramaswamy, V. Solid state 13C-NMR spectroscopy and XRD studies of commercial and pyrolytic carbon blacks. Carbon 2000, 38, 1279-1287. [CrossRef]

18. Difference between Conductive, Dissipative, Insulative, and Antistatic. Available online: Transforming-technologies.com/esd-fyi/difference-between-conductive-dissipative-and-insulative/ (accessed on 27 November 2019).

19. Tisserat, B.; Joshee, N.; Mahapatra, A.K.; Selling, G.W.; Finkenstadt, V.L. Physical and mechanical properties of extruded poly(lactic acid)-based Paulownia elongata biocomposites. Ind. Crop. Prod. 2013, 44, 88-96. [CrossRef]

20. Tisserat, B.; Reifschneider, L.; Joshee, N.; Finkenstadt, V.L. Properties of high density polyethylene—Paulownia wood flour composites via injection molding. BioResources 2013, 8, 4440-4458. [CrossRef]

21. Tisserat, B.; Reifschneider, L.; Joshee, N.; Finkenstadt, V.L. Evaluation of Paulownia elongata wood polyethylene composites. J. Thermoplast. Compos. Mater. 2013, 28, 1301-1320. [CrossRef]

22. Kaygin, B.; Kaplan, D.; Aydemir, D. Paulownia tree as an alternative raw material for pencil manufacturing. BioResources 2015, 10, 3426-3433. [CrossRef]

23. He, T.; Vaidya, B.N.; Perry, Z.D.; Parajuli, P.; Joshee, N. Paulownia as a medicinal tree: Traditional uses and current advances. Eur. J. Med. Plants 2016, 14, 1-15. [CrossRef]

24. Kalaycioglu, H.; Deniz, I.; Hiziroglu, S. Some of the properties of particleboard made from Paulownia. J. Wood Sci. 2005, 51, 410-414. [CrossRef]

25. Lopez, F.; Perez, A.; Zamudio, M.A.M.; de Alva, H.E.; García, J.C. Paulownia as raw material for solid biofuel and cellulose pulp. Biomass Bioenergy 2012, 45, 77-86. [CrossRef]

26. Vaughn, S.F.; Dinelli, F.D.; Tisserat, B.; Joshee, N.; Vaughan, M.M.; Peterson, S.C. Creeping bentgrass growth in sand-based root zones with or without biochar. Sci. Hortic. 2015, 197, 592-596. [CrossRef]

(C) 2019 by the author. Licensee MDPI, Basel, Switzerland. This article is an open access article distributed under the terms and conditions of the Creative Commons Attribution (CC BY) license (http://creativecommons.org/licenses/by/4.0/). 